\title{
Effect of chronic cardiopulmonary disease on survival after resection for stage Ia lung cancer
}

\author{
UGO PASTORINO, MAURIZIO VALENTE, VITTORIO BEDINI, \\ ANNAMARIA PAGNONI, GIANNI RAVASI
}

\begin{abstract}
From the Department of Thoracic Surgery and the Respiratory Physiopathology Service, Istituto Nazionale per lo Studio e la Cura dei Tumori, Milan, Italy
\end{abstract}

ABSTRACT The role of chronic cardiopulmonary disease as a risk factor for immediate and late

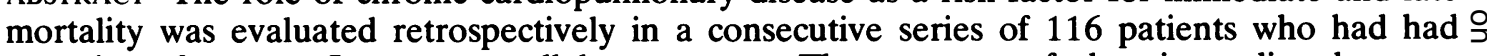
resections for stage Ia non-oat-cell lung cancers. The presence of chronic cardiopulmonary $\vec{c}$ disease was diagnosed on the clinical history and preoperative assessment of lung and heart function $\mathbb{D}$ by traditional means. Patients with chronic cardiopulmonary disease showed a lower five-year $\frac{\mathbb{\Phi}}{\overparen{D}}$ survival rate than controls-35\% versus $53 \%(\mathrm{p}<0.08)$. The difference increased and became $\frac{3}{6}$ significant if besides having cardiopulmonary disease the patient was over 60 years of age or had $\stackrel{\Phi}{\leftrightarrows}$ had a pneumonectomy-30\% versus $52 \%(\mathrm{p}<0.025)$. A higher operative mortality was the $\overrightarrow{0}$ main reason for the lower observed survival. Nevertheless, survival of patients at risk exceeded $\stackrel{\infty}{N}$ $30 \%$ in each subgroup, being $33 \%$ for patients over 60 undergoing pneumonectomy. In our series the benefits of resection of lung cancer in patients with impaired cardiopulmonary function were greater than the risks of perioperative and later death even in the groups with a poorer $\frac{\overline{0}}{0}$ prognosis.

The aetiological relationship between lung cancer and chronic obstructive lung disease is still controversial. The main causal factor in lung cancer, tobacco smoking, is also a prominent cause of both chronic bronchitis and chronic obstructive lung disease. ${ }^{1}$ Nevertheless, several prospective studies have shown no association between lung cancer and chronic obstructive lung disease, ${ }^{23}$ or between chronic bronchitis and the development of irreversible obstructive disease. ${ }^{1}$ A similar aetiological linkage with lung cancer appears for chronic cardiovascular disease, ${ }^{45}$ and the combination of lung cancer and chronic cardiopulmonary disease among heavy smokers is a common clinical problem, which often precludes the chance of curative treatment owing to a high operative risk. In stage I lung cancer the high probability of cure and the lesser resection required mean that surgical treatment is possible for many patients with impaired cardiopulmonary function. There is, however, an increased risk of immediate or later death if we accept the estimate of some authors of the poor life expectancy of patients with chronic obstructive lung disease. $^{6}$

Address for reprint requests: Dr Ugo Pastorino, Istituto Nazionale Tumori, via Venezian 1, 20133 Milan, Italy.
We carried out a retrospective evaluation of the $\frac{3}{3}$ prevalence and effect on survival of cardiopulmonary disease, assessed preoperatively in a consecutive series of patients who had resections for stage $I$ lung cancers, to establish its importance as a cause of death.

\section{Patients and methods}

We reviewed the clinical records of 116 consecutive patients who had resections for stage Ia (T1-T2, 음 NO, of UICC 1978) non-oat-cell lung cancer at the $>$ National Cancer Institute of Milan from January을 1974 to December 1977. One hundred and ten were N men and six women and their age ranged from 41 to 77 years (mean 58). Pathologically, the tumour was 0 graded $\mathrm{T} 1$ in 18 cases and $\mathrm{T} 2$ in 98 . Thirty-two patients underwent pneumonectomy, 80 lobectomy or bilobectomy, and four sublobar resection. 6 Tumour recurrence was found, during strict followup, in 45 patients $(39 \%)$, and was responsible for ? $68 \%$ of all observed deaths. A new primary tumour 0 occurred in two patients, who were otherwise free $\stackrel{\vec{P}}{\vec{P}}$

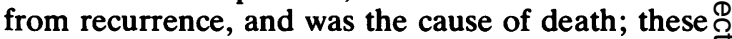
subjects were included in the group of patients with $\stackrel{\mathbb{Q}}{\stackrel{Q}{Q}}$ no recurrence. 
On the basis of the clinical history and the preoperative assessment of lung and cardiovascular function each patient was classified as having or not having chronic lung disease or cardiovascular disease, or both. Our criteria for this were objective, strictly following those proposed by Khalil' for the classification of "moderate operative risk"- that is, a risk that does not preclude pulmonary resection. Chronic cardiopulmonary disease was diagnosed in the presence of any of the following features: angina pectoris, myocardial infarction within the last two years, serious cardiac arrhythmias and conduction abnormalities, valvular heart disease, pulmonary heart disease, systemic hypertension (diastolic 110 $\mathrm{mm} \mathrm{Hg}$ ), serious peripheral arterial disease, a $35 \%$ reduction in predicted forced respiratory volume in one second, a $40 \%$ reduction in predicted forced vital capacity, or a residual volume greater than $40 \%$ of total lung capacity. Cumulative survival, including operative mortality, was computed by the life-table method after a minimum follow-up period of 42 months. Statistical analysis of the differences in survival was performed by the log-rank test, using the stratification method for the management of confounding factors, as suggested by Peto et al. ${ }^{8}$ Besides the cardiopulmonary risk, other factors such as age, sex, tumour extent, and volume of resection were examined to see whether they had a significant impact on survival. The role of cardiopulmonary disease was then investigated by separate analysis of non-cancer mortality, patients who died from tumour recurrence being considered as if they were lost to follow-up.

\section{Results}

According to our criteria, 60 patients $(51 \%)$ were affected by chronic cardiopulmonary disease, 37 of them by chronic lung disease, 11 by cardiovascular disease, and 12 by combined heart and lung disease. Perioperative death occurred in six of the 116 cases $(5.2 \%)$, but it was five times as frequent in the group at risk as in the group of patients without cardiopulmonary disease $(8.3 \%$ versus $1.7 \%$-table 1$)$. The increased operative mortality occurred principally in the group with chronic obstructive lung disease. The overall cumulative survival at five years was $44 \%$. (See fig 1 , in which operative mortality is both included and excluded.)

The group of patients with chronic cardiopulmonary disease, considered as whole, showed a fiveyear survival of $35 \%$, compared with $53 \%$ of patients without cardiopulmonary risk; but the difference was not statistically significant $(p=0.08-$ fig 2). On the other hand, the age of patients significantly affected survival (for age under 60 ver-
Table 1 Operative mortality in relation to cardiopulmonary disease

\begin{tabular}{lclc}
\hline Condition of patient & $\begin{array}{l}\text { No of } \\
\text { cases }\end{array}$ & $\begin{array}{l}\text { Operative } \\
\text { deaths }\end{array}$ & $\begin{array}{l}\text { Mortality } \\
(\%)\end{array}$ \\
\hline $\begin{array}{l}\text { Without cardiopulmonary } \\
\text { disease }\end{array}$ & 56 & 1 & $1 \cdot 7$ \\
$\begin{array}{l}\text { With cardiopulmonary } \\
\text { disease }\end{array}$ & 60 & 5 & $8 \cdot 3$ \\
$\begin{array}{l}\text { Pulmonary } \\
\text { Cardiac }\end{array}$ & 37 & 4 & $10 \cdot 8$ \\
$\quad$ Both & 11 & -1 & $8 \cdot 3$ \\
Totals & 116 & 6 & $5 \cdot 2$ \\
\hline
\end{tabular}

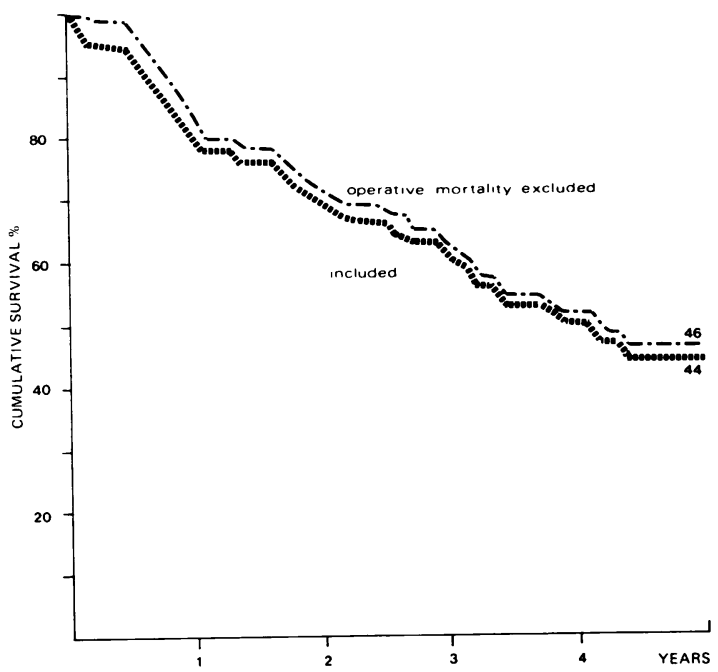

Fig 1 Overall cumulative survival excluding and including operative mortality.

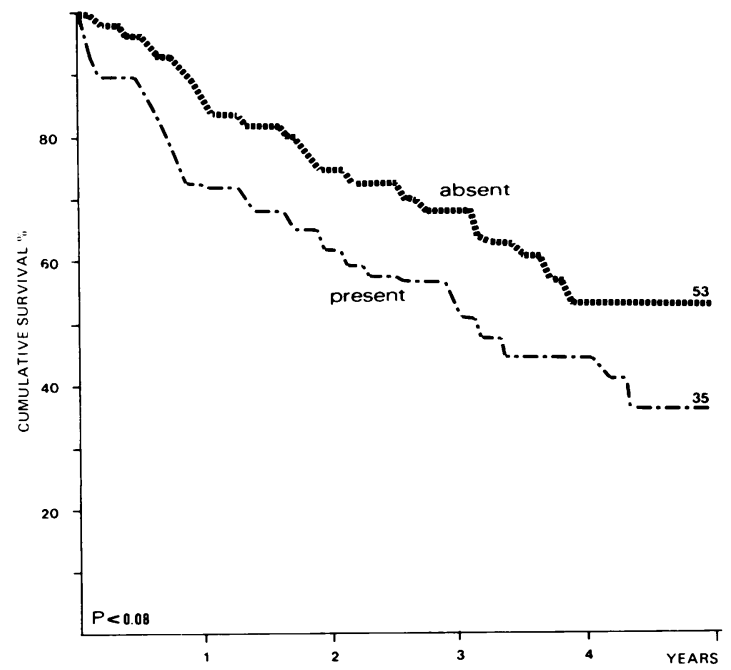

Fig 2 Survival according to presence and absence of cardiopulmonary risk. 
Table 2 Total deaths and deaths from recurrence of lung cancer by age and presence or absence of chronic cardiopulmonary disease

\begin{tabular}{|c|c|c|c|c|}
\hline \multirow[t]{2}{*}{ Age } & \multirow{2}{*}{$\begin{array}{l}\text { Cardio- } \\
\text { pulmonary } \\
\text { disease }\end{array}$} & \multirow{2}{*}{$\begin{array}{l}\text { No of } \\
\text { Patients }\end{array}$} & \multicolumn{2}{|c|}{ No of deaths } \\
\hline & & & Total & $\begin{array}{l}\text { From recurrence } \\
\text { of cancer }\end{array}$ \\
\hline $\begin{array}{l}<60 \mathrm{y} \\
\geqslant 60 \mathrm{y} \\
\text { Total }\end{array}$ & $\begin{array}{l}- \\
+ \\
+ \\
+\end{array}$ & $\begin{array}{r}34 \\
27 \\
22 \\
33 \\
116\end{array}$ & $\begin{array}{l}12 \\
15 \\
14 \\
22 \\
63\end{array}$ & $\begin{array}{l}10 \\
11 \\
11 \\
10 \\
42\end{array}$ \\
\hline
\end{tabular}

sus 60 or over $p<0.025$ ); but sex, tumour extent, and volume of resection if considered by themselves had no significant effect on survival. The effect of cardiopulmonary risk was then stratified for age. Table 2 shows the numbers of patients, deaths, and deaths due to recurrence of the tumour according to age and the presence of cardiopulmonary risk. An appreciable difference in survival by age and risk appeared only in the group of patients under 60 years (fig 3$)$, though not significant $(p<0 \cdot 12)$, while over 60 the presence of cardiopulmonary risk did not result in a lower survival rate. From a statistical point of view, the effect of chronic disease was reduced by age standardisation (age standardised $p$ $=0 \cdot 215)$. This fact suggests that the observed difference in survival according to cardiopulmonary risk was partly attritutable to the age of patients.

The relation between risk and volume of resection was also examined. Major resections did not appear to have a significantly greater effect on survival in

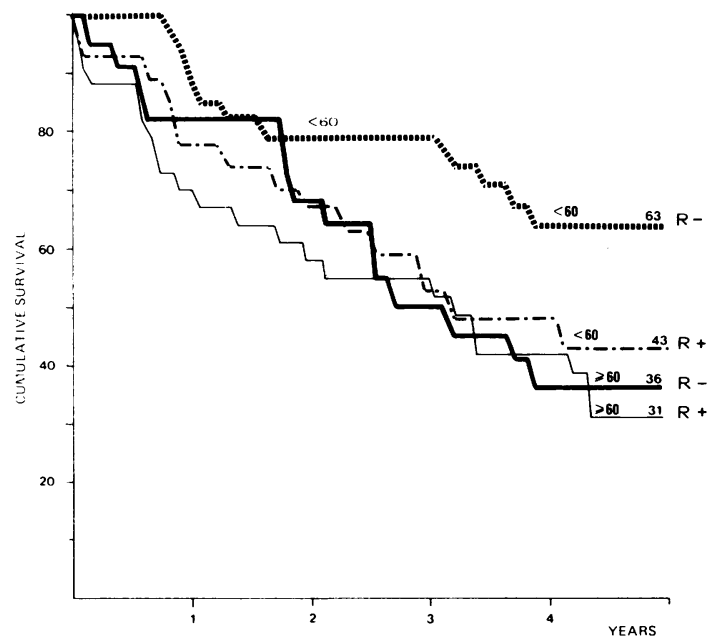

Fig 3 Survival by age (under 60 years and 60 or more) and cardiopulmonary risk ( $R-=$ no risk; $R+=$ risk present). patients at cardiopulmonary risk than the lesser resections, and even in the less favourable condi- $\vec{O}$ tions the observed survival exceeded $30 \%$ (for 듬 example, cardiopulmonary risk and pneumonec- $\overline{\bar{m}}$ tomy in patients over $60,33 \%$ ). Nevertheless, if we $\overparen{\Phi}$ consider at risk only those patients with cardiopulmonary disease who also had a pneumonectomy or ${ }^{\text {s }}$ were over 60 , the overall difference in survival $\overrightarrow{0}$ increased and became significant $(30 \% v 52 \%, \mathrm{p}<\overrightarrow{\overrightarrow{\vec{H}}}$ $0 \cdot 025)$. The role of cardiopulmonary disease was $\stackrel{\omega}{\mathscr{N}}$ then evaluated on the basis of the survival curves for $\overrightarrow{\vec{x}}$ separate causes of death. Figure 4 shows the non- $\dot{\omega}$ cancer mortality according to the preoperative risk, where all patients who had died from cancer recurrence were considered as lost to follow-up; survival $\propto$ rates were $88 \%$ and $65 \%(\mathrm{p}<0.025)$. Separate analysis of the effect of chronic pulmonary disease $\stackrel{5}{-}$ showed that this had a lesser impact on survival, $\vec{s}$ though all the perioperative deaths occurred in this $\mathbb{D}$ group, thus confirming the lack of importance of $\mathbb{\Phi}$ cardiovascular disease as a component of the post- 금 operative risk. Unfortunately, a more detailed $\stackrel{\Phi}{-}$ analysis of this subject was not possible owing to our $\vec{\bullet}$ small sample. The exclusion of operative mortality $\underset{N}{\infty}$ greatly reduced the difference in survival on all the curves, thus indicating that the role of chronic cardiopulmonary disease was mainly attributable to the higher operative mortality. Nevertheless, the difference between the groups remained significant for $\frac{\mathscr{}}{\varnothing}$ non-cancer deaths and also when further risk fac- $\varrho$ tors, such as age over 60 or pneumonectomy, were $\overrightarrow{\overrightarrow{0}}$ added to cardiopulmonary disease.

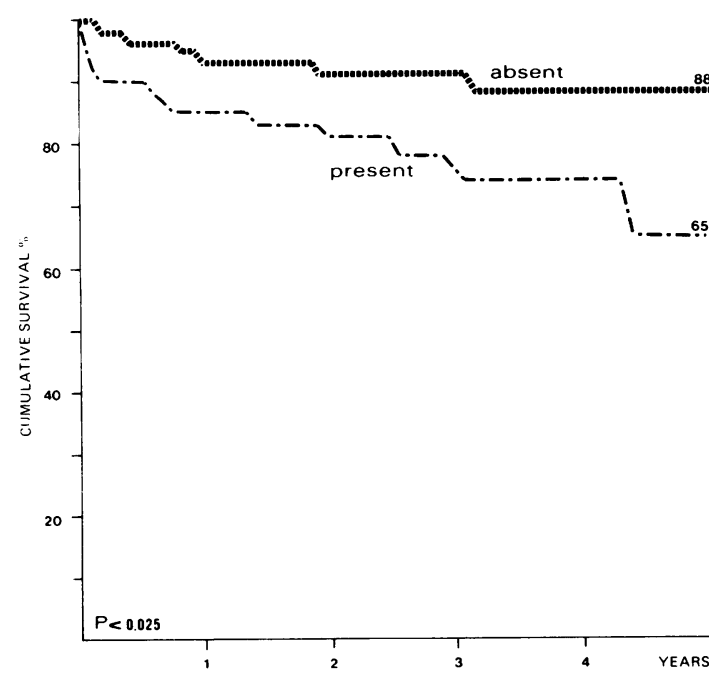

Fig 4 Survival by non-neoplastic causes of death according to presence and absence of cardiopulmonary risk. $\stackrel{\unrhd}{\unrhd}$ 


\section{Discussion}

The proportion of patients at risk from cardiopulmonary disease was high in our sample $(51 \%)$, reflecting both its high prevalence in association with lung cancer and our attitude toward resection of clinical stage I lung cancer in patients with concomitant disease. On the other hand, we selected patients with stage Ia lung cancer, not only to have the group with the highest chance of long-term survival but also to obtain the largest proportion of the factor under study. Chronic cardiopulmonary disease resulted in a lower long-term survival rate whichever group was considered, but the observed difference reached significance only with the separate analysis of non-cancer mortality. The association of cardiopulmonary disease and age over 60 or pneumonectomy resulted in a further and significant reduction of survival, representing a true negative prognostic factor. As we expected, lower observed survival rate proved to be partly attributable to the higher operative mortality (five times greater in the group at risk); but it remained after elimination of the operative deaths from survival curves. Data on the natural history of resected stage I lung cancer after resection, derived from hospital statistics, have generally lacked information on the true cause of death, an average $30 \%$ of all resected patients dying without evidence of recurrence; ${ }^{10}$ the proportion was $18 \%$ in our sample. Causes of death in such patients clearly include clinically occult recurrences and new primary cancers, as well as non-neoplastic conditions. It is our conviction that some distant metastases, hard to detect by traditional follow-up methods (for example, in the adrenal gland), can be responsible for some of the deaths without recurrence. But we are convinced too that an important proportion of those deaths could be attributable to the chronic cardiopulmonary disease. This means not that pulmonary resection should be avoided in patients with impaired heart and lung function but exactly the opposite: the curative potential of surgery in stage Ia lung cancer was probably greater than the observed survival would suggest, since causes of death other than cancer recurrence are very likely. The survival rate of patients at risk was satisfying even in the groups with a poorer expected survival rate, such as the group over 60 years undergoing pneumonectomy, and always exceeded $30 \%$ at five years. A possible conclusion of this study is that the benefit of cancer resection in patients with impaired cardiopulmonary function was greater than the risk of perioperative and late death even for elderly patients undergoing major resections. Nevertheless, further improvement in the immediate and long-term care of patients after resections for stage I lung cancer seems advisable in the case of those at risk from chronic cardiopulmonary disease.

\section{References}

${ }^{1}$ Fletcher C, Peto R. The natural history of chronic airflow obstruction. Br Med J 1977;i:1645-8.

${ }^{2}$ Caplin M, Fenstenstein F. Relation between lung cancer, chronic bronchitis, and airways obstruction. $\mathrm{Br}$ Med J 1975;iii:678-80.

${ }^{3}$ Scherrer L, Zeller C, Scherrer M. Smoking, chronic bronchitis, bronchiolar obstruction, and lung cancer. Schweiz Med Wochenschr 1978;108:556-9.

4 Aronow WS. Effect of cigarette smoking and carbon monoxide on coronary heart disease. Chest 1976;70:514-8.

${ }^{5}$ Schievelbein $\mathrm{H}$. The evidence for nicotine as an etiological factor in cardiovascular disease. In: Proceedings of the Third World Conference on Smoking and Health. Vol 1. Washington: US Department of Health, Education, and Welfare, 1976:297-307.

- Burrows B, Earle RH. Prediction of survival in patients with chronic airway obstruction. Am Rev Respir Dis 1969;99:865-71.

${ }^{7}$ Khalil Ali M, Ewer MS. Preoperative cardiopulmonary evaluation of patients undergoing surgery for lung cancer. Cancer Bull 1980;32:100-4.

seto R, Pike MC, Armitage P, et al. Design and analysis of randomised clinical trials requiring prolonged observation of each patient. II. Analysis and examples. Br J Cancer 1977;35:1-39.

' Kemeny MM, Block LR, Braun DW, Martini N. Results of surgical treatment of carcinoma of the lung by stage and cell type. Surg Gyn Obst 1978;147:865-71.

${ }^{10}$ Mountain CF, Hermes KE. Management and implications of surgical staging studies. In: Muggia F, Rozencweigh $\mathrm{M}$, eds. Lung cancer: progress in therapeutic research. New York: Raven Press, 1979:233-42. 